\title{
Comparative Characterization of Multiscale Carbon Fiber Composite with Long and Short MWCNTs at Higher Weight Fractions
}

\author{
Michael Zimmer, ${ }^{1}$ Qunfeng Cheng, ${ }^{1}$ Shu Li, ${ }^{1}$ James Brooks, ${ }^{2}$ \\ Richard Liang, ${ }^{1}$ Ben Wang, ${ }^{1}$ and Chuck Zhang ${ }^{1}$ \\ ${ }^{1}$ High-Performance Materials Institute, Florida State University, 2005 Levy Avenue, Tallahassee, FL 32310, USA \\ ${ }^{2}$ National High Magnetic Field Laboratory, Florida State University, A311 1800 E. Paul Dirac Dr., Tallahassee, FL 32310, USA \\ Correspondence should be addressed to Michael Zimmer, mmzimmer@gmail.com
}

Received 2 January 2012; Revised 26 March 2012; Accepted 11 April 2012

Academic Editor: Marcio Rodrigo Loos

Copyright (C) 2012 Michael Zimmer et al. This is an open access article distributed under the Creative Commons Attribution License, which permits unrestricted use, distribution, and reproduction in any medium, provided the original work is properly cited.

\begin{abstract}
There are documented advantages to using carbon nanotubes (CNTs) in composites for various property enhancements. However, to date, only limited studies have been conducted on using of longer CNTs over $1 \mathrm{~mm}$ in length. This study used long multiwalled carbon nanotubes (LMWCNTs) and their longer extended networks to test multiple properties in thermal conductivity, electrical conductivity, mechanical strength, and modulus and then compared these properties to those of shorter multi-walled carbon nanotubes (SMWCNTs). For carbon fiber-reinforced composites, the longer graphite paths from LMWCNTs in the matrix were expected to improve all properties. The longer networks were expected to allow for more undisturbed phonon transportation to improve thermal conductivity. This in turn relates to improved electrical conductivity and better mechanical properties. However, results have shown that the LMWCNTs do not improve or decrease thermal conductivity, whereas the shorter MWCNTs provide mixed results. LMWCNTs did show improvements in electrical, mechanical, and physical properties, but compared to shorter MWCNTs, the results in other certain properties varied. This perplexing outcome resides in the functioning of the networks made by both the LMWCNTs and shorter MWCNTs.
\end{abstract}

\section{Introduction}

The addition of carbon nanotubes (CNTs) to improve various mechanical and electrical properties in fiber-reinforced composites has undergone numerous studies [1-6]. A great deal of research has been published on the thermal conductivity improvements of CNT/polymer-based composites [712]. However, very few studies have been conducted to show the thermal conductivity characteristics of fiber-reinforced composites with CNTs enhancements [13]. All studies were done with the use of single-walled carbon nanotubes (SWCNTs) and multiwalled carbon nanotubes (MWCNTs) of lengths ranging from $10 \mathrm{~nm}$ to $80 \mu \mathrm{m}[8,11,13]$ when length dimensions were provided. One study showed the delamination toughness of what they state is long multiwalled carbon nanotubes [14] with a maximum length of $80 \mu \mathrm{m}$. To date, however, no studies have shown the thermal conductivity, electrical conductivity, and mechanical properties of millimeters-long multiwalled carbon nanotubes (LMWCNTs) in fiber-reinforced composites.

This study tests the LMWCNTs versus shorter multiwalled carbon nanotubes (SMWCNTs) at a range of $0.5 \mathrm{wt} \%$ to $10.0 \mathrm{wt} \%$. This is one of the first introductions of extremely high loadings of CNTs in polymer composites. The limiting factor to having high loading additives in viscous resins is the dispersion quality. One method to overcome the thick viscosity of epoxy resins is using solvents to dilute the mixture to use high-speed shear mixing with blades. The disadvantage to this process is removing the solvent $100 \%$ and not, ultimately, affecting the resin composition. Using alternative shear mixers without solvents has been discovered in this study and results in uniform dispersion to accomplish high CNT-loaded composites. The LMWCNTs used are from Nanotech Labs CVD grown to $2 \mathrm{~mm}$ in length and 


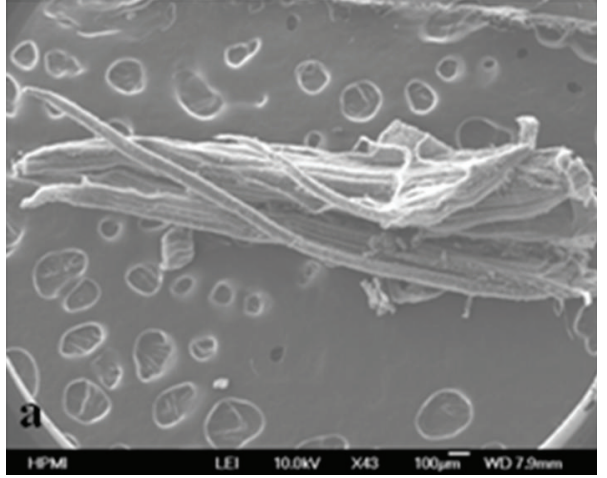

(a)

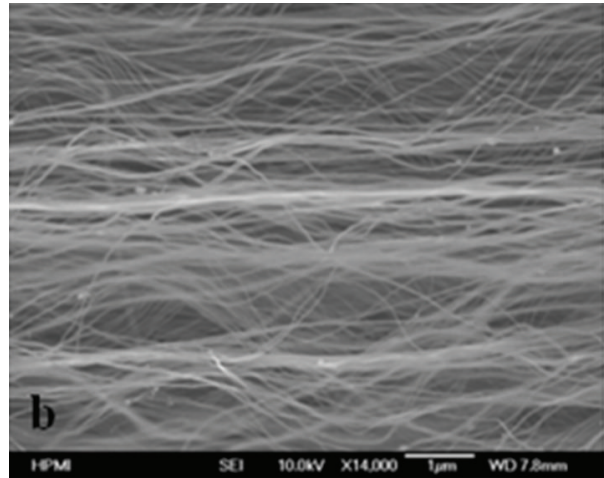

(b)

FIGURE 1: SEM image of long MWCNTs: (a) full view of a piece of the LMWCNTs forest, (b) magnified image of forest.

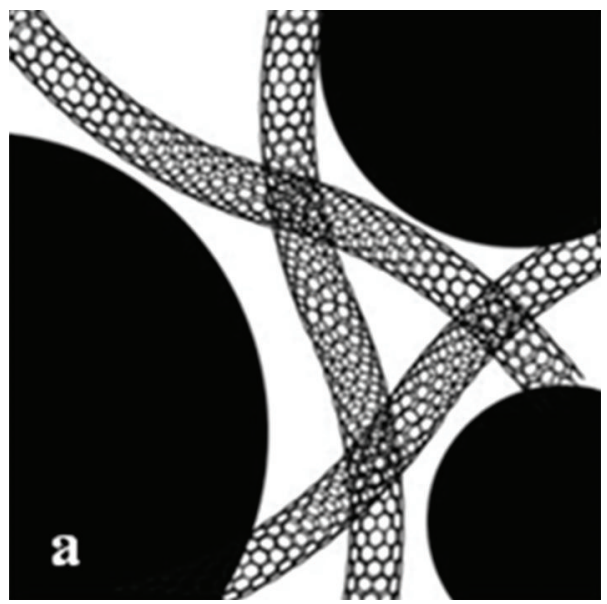

(a)

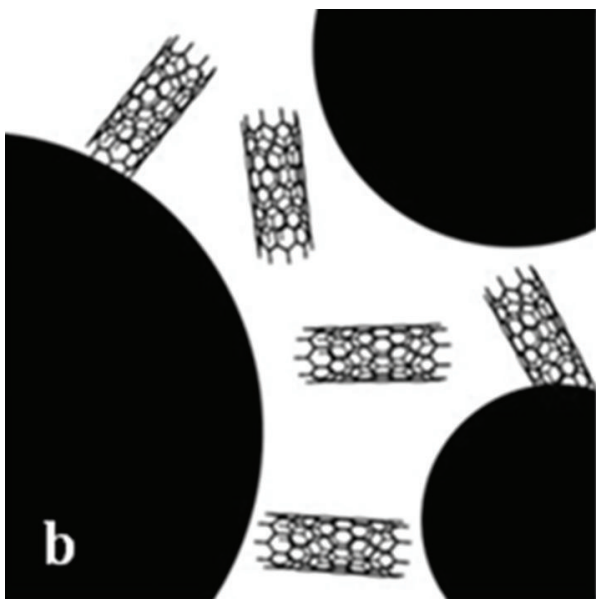

(b)

FIgURE 2: Comparison of LMWCNTs (a) and SMWCNTs (b) introduced in fiber-reinforced composite.

compare them to 1 micron length high-purity MWCNTs from Bayer. Figure 1 shows SEM images confirming the length of LMWCNTs up to $1.5 \mathrm{~mm}$.

Using LMWCNT and SMWCNT in composites would be to overcome the primary weakness of low thermal conductivity in the matrix of fiber-reinforced composites. Studies have been conducted to improve the thermal characteristics of polymers with the additives of CNTs or other nanoparticles and fillers $[15,16]$. The interlaminar interface in composite structures is a resin-rich layer. Improving the thermal performance of the interlaminar interface would increase the through-thickness thermal conductivity. Prior works for enhancing the interlaminar conductivity through the use of nanostructuring have shown good results using carbon black [17].

Phonon thermal conductivity is the principal mechanism of heat transfer that is responsible for thermal conductivity of composite materials $[18,19]$. Phonon transport is known as phonon-phonon scattering or normal scattering [18]. Thermal conductivity benefits from normal scattering. Having a continuous conductive path that is free of defects and disruptions with the molecular structure that is crystallinelike, such as metal or graphite lattice, would promote an effective and efficient means of producing high thermal conductivity in composites [18-22]. The polymers' noncrystalline structure hinders the normal scattering [23].

One of the studies investigates if the use of LMWCNTs would provide longer network paths for more phonon transportation using the superior graphite lattice of the nanotube to overcome the polymer's scattering effects. Figure 2 is a representation of the LMWCNT in fiberreinforced composite compared to shorter MWCNTs. The improved, longer networks should minimize the defects and disruptions the phonons encounter and reduce the resistance along the heat flow path. The electrical conductivity should also benefit from these principles as its conductivity is dictated by electron transportation [18]. With long networks, the electrons should travel with less resistance throughout the composite. Along with the thermal and electrical performance of the composite with LMWCNTs, the mechanical properties should benefit as well. It is expected that the LMWCNT will outperform SMWCNT. 


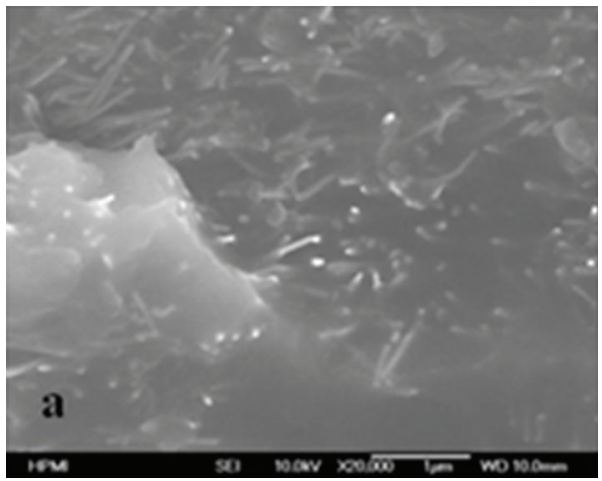

(a)

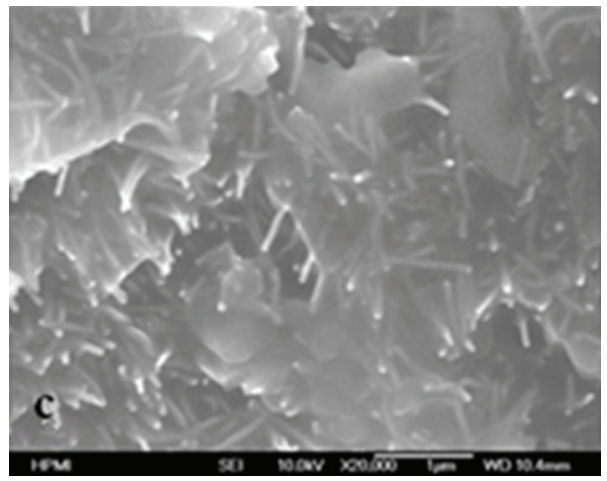

(c)

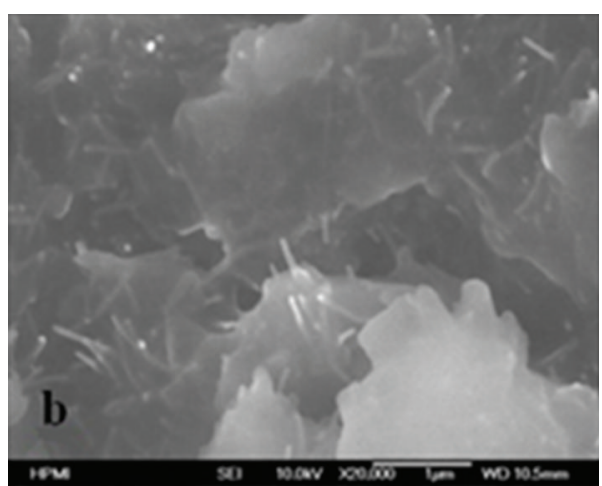

(b)

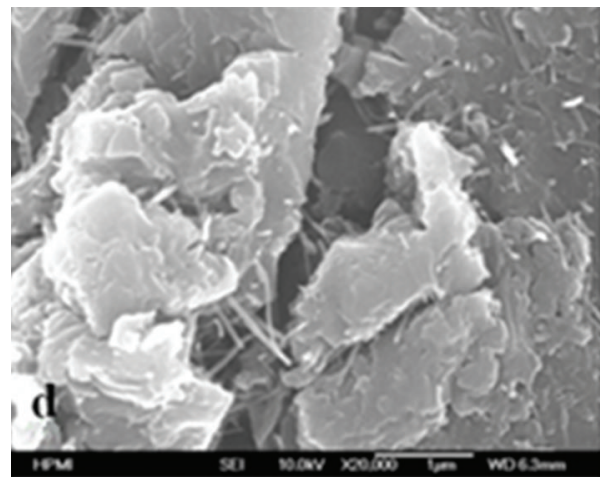

(d)

FIGURE 3: SEM of LMWCNT multiscale composite for (a) $0.5 \mathrm{wt} \%$, (b) $1.0 \mathrm{wt} \%$, (c) $5.0 \mathrm{wt} \%$, and (d) $10.0 \mathrm{wt} \%$.

\section{Experiment}

2.1. Fabrication. LMWCNTs and SMWCNTs were introduced into fiber-reinforced composites by creating a highly loaded nanotube epoxy mixture. The epoxy/nanotube mixture (Epon 862 and Nanotech Labs LMWCNTs) was made using Exakt triple roller mills for shear mixing. Four MWCNT concentrations were mixed at $0.5 \mathrm{wt} \%, 1.0 \mathrm{wt} \%$, $5.0 \mathrm{wt} \%$, and $10 \mathrm{wt} \%$. The shear mixing process had 3 controllable parameters to produce uniform mixtures: time span of mixing, gap size between the rollers, and speed of the rollers. As the gap size decreased to $5 \mu \mathrm{m}$ and the speed increased, the MWCNT clumps broke down resulting in higher shearing of the material. The length of time the material underwent the process ensured a uniform mixture.

The MWCNTs/Epon 862 mixture was then incorporated into IM7 carbon fabric for composite fabrication. The fabrication of the composite was performed as a 4-layer hand-layup process using compression molding for curing. The curing cycle was at $177^{\circ} \mathrm{C}$ for 4 hours. A 55\% volume fraction of fiber was achieved for each sample using the controlled molding process. Five, $50 \times 50 \times 1 \mathrm{~mm}$ sample panels of each CNT concentration were made in which sample pieces were cut from for characterization testing.

2.2. Quality Test. SEM imaging was used to visually identify uniformity of the MWCNTs/Epon 862 mixture in the composite. Figures 3 and 4 show the SEM image results for the LMWCNTs and SMWCNTs multiscale composites, respectively. The LMWCNTs could be identified at lower magnifications up to $\times 2,500$, whereas the SMWCNTs required at least $\times 60,000$ for $0.5 \mathrm{wt} \%$ and $1.0 \mathrm{wt} \%$. At $\times 20,000$ magnification, the SMWCNTs could be identified for $5.0 \mathrm{wt} \%$ and $10 \mathrm{wt} \%$. The images show random CNT orientation and good uniformity of the mixture.

Between the C-Scan and SEM tests, the composites for both LMWCNTs and SMWCNTs showed little or no defects and had a uniformity in material that made for reliable testing and analysis. Samples were polished on the surface to remove any roughness and underwent a sonication bath at 15 minute intervals to clean any debris that might affect any test results.

\section{Results}

3.1. Thermal Characterization. Samples were cut into $10 \times$ $10 \mathrm{~mm}$ squares for thermal diffusivity testing using Netzsch LFA 457 MicroFlash system. Netzsch LFA 457 uses a laser flash method for absolute diffusivity measurement results. Each sample was tested with a reference sample using Pyrex 7740 for specific heat $\left(C_{p}\right)$ calculation using the LFA 457. Due to the samples' anisotropic nature, using DSC would not reveal reliable specific heat results. The LFA 457 can test the thermal diffusivity while simultaneously extrapolating the $C_{p}$ measurement of the unknown samples. Gathering the diffusivity $(\alpha)$ results and the measured density $(\rho)$ and $C_{p}$, 


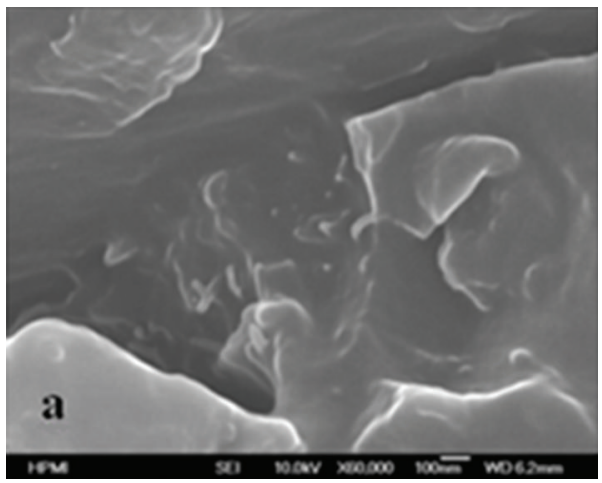

(a)

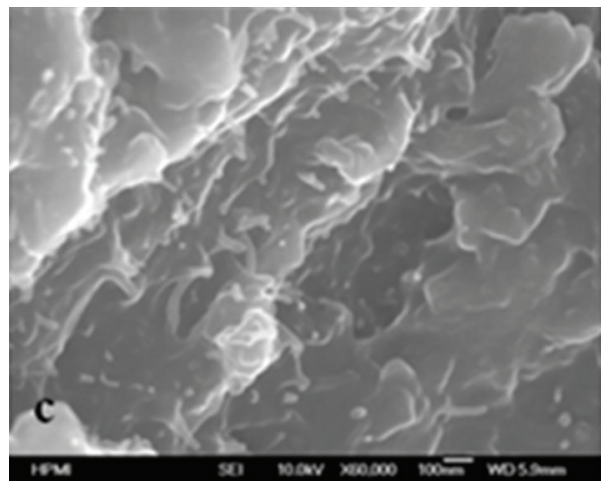

(c)

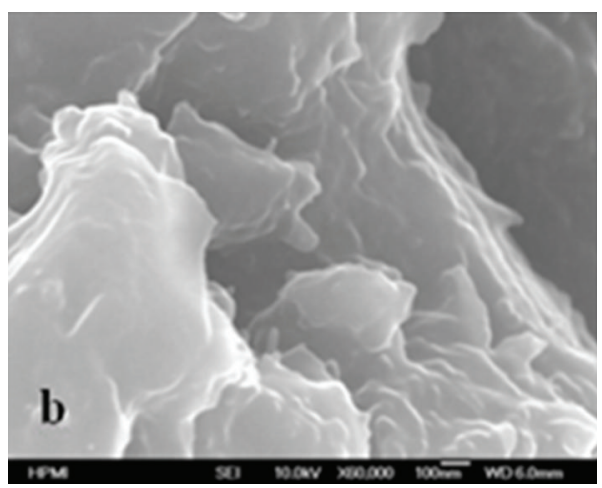

(b)

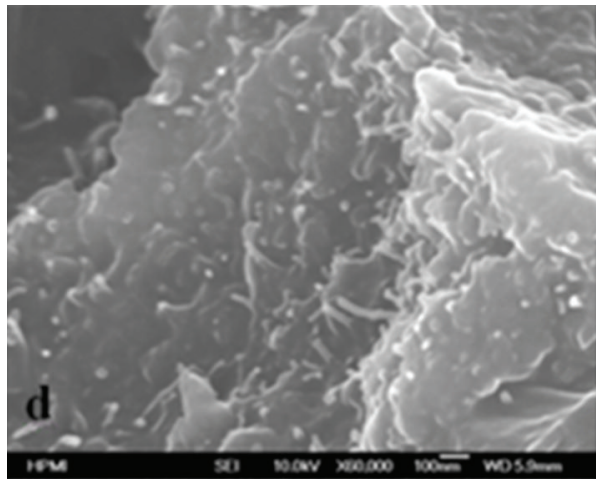

(d)

Figure 4: SEM of SMWCNTs multiscale composite for (a) $0.5 \mathrm{wt} \%$, (b) $1.0 \mathrm{wt} \%$, (c) $5.0 \mathrm{wt} \%$, and (d) $10.0 \mathrm{wt} \%$.

the thermal conductivity $(K)$ of the samples was calculated using (1). Figures 5 and 6 show the thermal conductivity results for both types of samples taking the average of 6 separate tests:

$$
K=\alpha \cdot \rho \cdot C_{p}
$$

The results of the LMWCNT samples were other than what was expected. It was thought that the thermal conductivity values would increase with increased LMWCNT loading. Only the samples with $10 \mathrm{wt} \%$ loading had a clear advantage. The other samples were approximately the same thermal conductance at each temperature range. The SMWCNT samples had an inverse effect compared to the LMWCNT samples but have a clear definition at which loading performs better. Thermal conductivity at $0.5 \mathrm{wt} \%$ of SMWCNTs was superior to all samples. As the loading increased, the thermal conductivity values decreased below that of the neat sample. Thermally conductive materials typically have high diffusivity and specific heat values. It was expected that the multiscale composites would show higher values across all loading levels compared to the neat sample. Table 1 shows an excerpt of the specific heat and thermal diffusivity of both samples. The thermal conductivity, therefore, showed no improvements. Only the results of the $10.0 \mathrm{wt} \%$ sample showed marginal improvements. This could be due to the induced loading.

The thermal conductivity results for LMWCNT and SMWCNT have altered perception of the thermal behavior

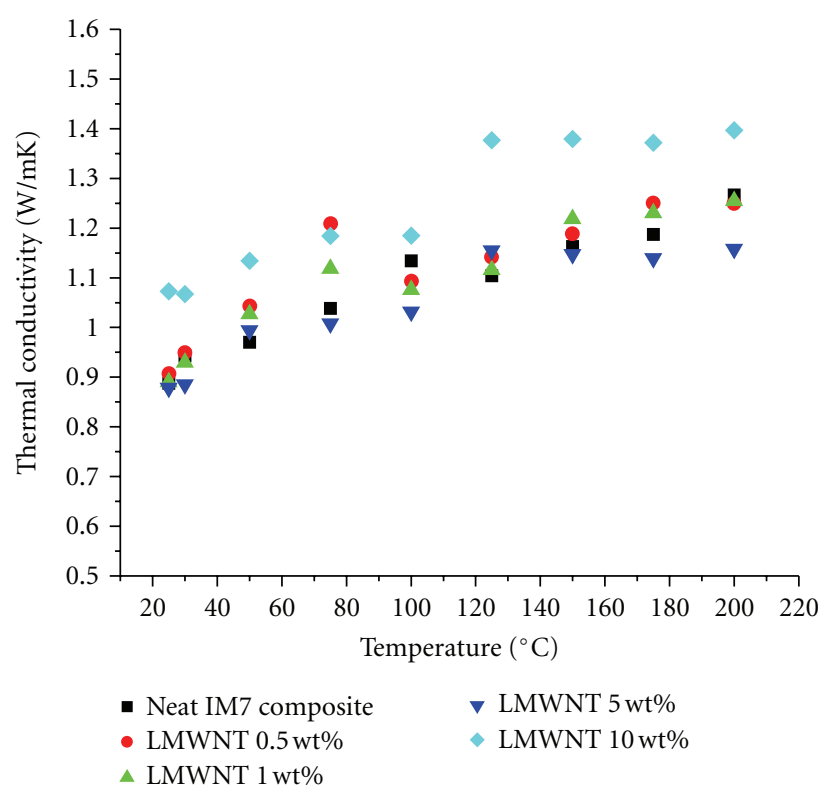

FIGURE 5: LMWCNT multiscale composite thermal conductivity.

expected in multiscale composites. The idea to add high conductive additives to composites to increase performance must now consider several factors: the size of the material, loading, and possible material structure and orientation 
TABLE 1: Thermal diffusivity and specific heat values of LMWNT and SMWNT samples.

\begin{tabular}{|c|c|c|c|c|c|}
\hline & \multicolumn{2}{|c|}{ LMWNT } & \multicolumn{2}{|c|}{ SMWNT } \\
\hline & & $\alpha$ & $C_{p}$ & $\alpha$ & $C_{p}$ \\
\hline \multirow{4}{*}{$25^{\circ} \mathrm{C}$} & $0.5 \mathrm{wt} \%$ & 0.662 & 0.863 & 0.695 & 0.851 \\
\hline & $1.0 \mathrm{wt} \%$ & 0.642 & 0.882 & 0.622 & 0.811 \\
\hline & $5.0 \mathrm{wt} \%$ & 0.641 & 0.885 & 0.618 & 0.786 \\
\hline & $10.0 \mathrm{wt} \%$ & 0.528 & 1.277 & 0.490 & 0.943 \\
\hline \multirow{4}{*}{$50^{\circ} \mathrm{C}$} & $0.5 \mathrm{wt} \%$ & 0.648 & 1.014 & 0.674 & 0.982 \\
\hline & $1.0 \mathrm{wt} \%$ & 0.625 & 1.045 & 0.608 & 0.955 \\
\hline & $5.0 \mathrm{wt} \%$ & 0.617 & 1.034 & 0.606 & 0.859 \\
\hline & $10.0 \mathrm{wt} \%$ & 0.493 & 1.456 & 0.476 & 1.052 \\
\hline \multirow{4}{*}{$100^{\circ} \mathrm{C}$} & $0.5 \mathrm{wt} \%$ & 0.615 & 1.120 & 0.638 & 1.246 \\
\hline & $1.0 \mathrm{wt} \%$ & 0.592 & 1.156 & 0.575 & 1.209 \\
\hline & $5.0 \mathrm{wt} \%$ & 0.582 & 1.136 & 0.572 & 1.014 \\
\hline & $10.0 \mathrm{wt} \%$ & 0.464 & 1.614 & 0.444 & 1.199 \\
\hline \multirow{4}{*}{$200^{\circ} \mathrm{C}$} & $0.5 \mathrm{wt} \%$ & 0.537 & 1.465 & 0.557 & 1.513 \\
\hline & $1.0 \mathrm{wt} \%$ & 0.516 & 1.547 & 0.502 & 1.495 \\
\hline & $5.0 \mathrm{wt} \%$ & 0.504 & 1.475 & 0.497 & 1.405 \\
\hline & $10.0 \mathrm{wt} \%$ & 0.387 & 2.276 & 0.371 & 1.720 \\
\hline
\end{tabular}

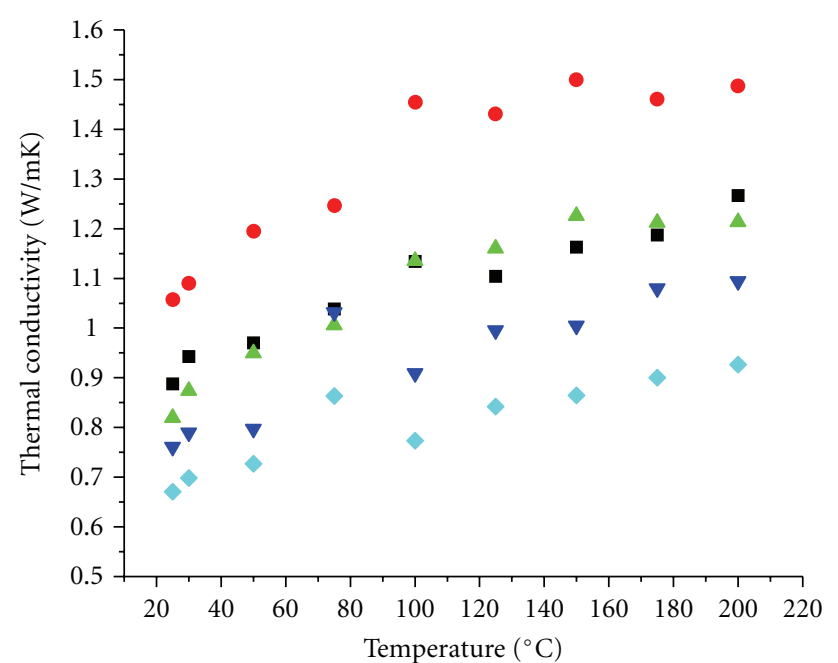

- Neat IM7 composite

- SMWNT $0.5 \mathrm{wt} \%$

จ SMWNT $5 \mathrm{wt} \%$

$\triangle$ SMWNT $1 \mathrm{wt} \%$

FIGURE 6: SMWCNT multiscale composite thermal conductivity.

in the composite. What is understood is that chemical composition of polymers will independently dictate the thermal conductivity. Low thermal excitation of polymers along the molecular chain could possibly be accounted for by diffusion of vibrational energy between atoms that relate to thermal transport [24]. Other factors must be present of the unchanging and lowering of thermal conductivity values in the composite samples.

A research group [25] looked at the thermal conductivity effects of carbon nanotube (CNT) networks. The study revealed that packed loadings of CNTs of high heat conductance behaved as thermal insulators [25]. This discovery is largely contributed to the multiple contact resistance or junctions of the CNTs that create interference effects on the transport of phonons [25].

Phonons can be impeded by position and vibration of atoms in neighboring planes [26]. This would be a possible explanation of the interference effects on the transport of phonons. With increased loading, there is more packing of MWCNTs where the scattering effects of the phonons in each MWCNTs disrupt the harmonic frequency of the neighboring phonon transportation in adjacent MWCNTs.

The diffused thermal conduction is also compounded by a well-known point that energy transfer between CNTs is affected by the interfacial resistance with the surrounding polymer [19]. Similarly, a major thermal resistance factor when dealing with multiscale composites is the thermal boundary resistance. The thermal boundary resistance is the increased heat resistance at the interface of two different materials $[24,26]$. As heat is applied to the system, the heat passes through the carbon fiber region with minimal decrease in conductivity. The moment the heat propagation reaches the boundary into the resin, a major heat loss occurs. Materials made with mismatched properties in phonon velocity, specific heat, and density show a more significant reduction in thermal conduction than with materials made with substituent parts of similar properties [19, 24, 27].

There are many contributing factors that play a role into the thermal effects observed from the LMWCNTs and SMWCNTs multiscale composites. In the case of the LMWCNTs, it is possible that the long networks snake around in multiple directions that could divert the paths other than the through-thickness direction as desired. Another theory is that the length of LMWCNTs does not create a ballistic 


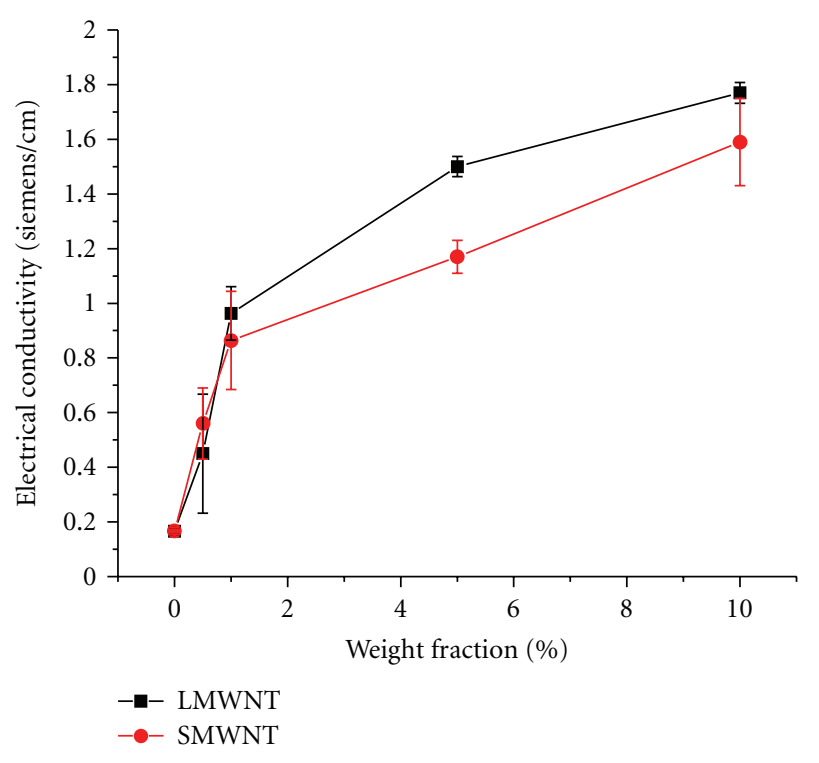

FIgURE 7: Electrical conductivity of LMWCNT and SMWCNT multiscale composite.

effect of phonons dispersing heat energy [19, 27] where the SMWCNTs at low loadings would. These results are some of the first to be seen at high loadings of carbon nanotubes in a multiscale composite.

3.2. Electrical Characterization. With the enhancement of LMWCNTs and SMWCNTs into the carbon fiber-reinforced system, the interlaminar regions were expected to increase the overall electrical properties of the composite. Improvements in the resistivity were evident when electrical conductivity tests using the 2-probe test were performed. Figure 7 shows the improved electrical conductivity through the thickness of the composites as the LMWCNTs and SMWCNTs loading increased.

The trend in the electrical resistance was outstanding relative to the thermal conductivity indifference. It was thought that the behavior of either the thermal or electrical properties would show a parallel behavior for the other; however, this was not the case. The difference in characteristics between thermal and electrical properties is that the electrical conductance is not disrupted by the multiple contact points or junctions or disrupted by the proximity of other MWCNTs [25]. These junctions were not dependent on the coupling strength between multiple MWCNTs $[25,28]$. The electrical conductivity had a strong relationship to the number of junctions made in the composite [29]. The increase in weight fraction of LMWCNTs and SMWCNTs created more contact points, decreasing the distance electrons need to tunnel through the polymer, effectively improving the electrical performance $[26,28-31]$. This also demonstrates that more electron tunneling occurred. The phenomena of tunneling overcame the contact resistance that thermal transport encounters. For thermal transport, these resistances and the multiple scattering effects created major barriers. The electrical performance can be greatly impacted when the system has low thermal conductivity as the samples did [28].

3.3. Mechanical Characterization. Figures 8 and 9 show the average of five tests of the flexural modulus and strength using a Shimadzu AGS-J microtensile tester. The testing showed mixed result where some samples performed better in modulus and others did better in strength. In another study, a similar outcome in flexural modulus was observed where the initial loadings of CNTs acted as defects, but as the loading increased, the modulus outperformed the neat sample [32]. It is hard to compare how well LMWCNTs really performed in relation to shorter MWCNTs. In one study, with $1.0 \mathrm{wt} \%$ of MWCNTs in a glass fiber system, modulus and strength improved [33]. A study using T650 and 862 resin system with $1.0 \mathrm{wt} \%$ of MWCNTs resulted in decreased modulus and strength [34].

The LMWCNT multiscale composite had little or no effect in resisting deformation as the flexural strength shows. The modulus would suggest that low loadings outperformed higher loadings. This is reasonable considering that with higher loadings the stiffness of the sample would increase. However, in the SMWCNT multiscale composite, the values of both strength and modulus spiked at $10.0 \mathrm{wt} \%$. This phenomenon was entirely unexpected. The Shimadzu was recalibrated, and fresh SMWCNT samples were tested again to validate the results with the same affect. Between the $5.0 \mathrm{wt} \%$ and $10.0 \mathrm{wt} \%$ loading range, the strength and modulus might be increasing. There was no literature published that could provide a valid explanation on the reasoning of the observed results for SMWCNT multiscale composites. Overall, the performance did follow the original theory that LMWCNTs and SMWCNTs would improve the mechanical performance. However, the LMWCNT samples did not show a clear advantage over the SMWCNT samples.

\section{Conclusion}

The uses of LMWCNTs in composites have yielded unique results. The expectation that the longer network paths of the LMWCNTs would provide better thermal performance at high loadings was proven false. Instead, they functioned more like insulators due to various interference effects and contact and boundary resistances on phonon transportation. Only did LMWCNT samples at $10 \mathrm{wt} \%$ showed a visible advantage. The SMWCNTs samples experienced degrading thermal conductivity by this same reasoning. However, the LMWCNTs' network proved to be exceptional on the electrical performance contributed by the increased junctions made in the polymer system with the carbon fibers compared to the SMWCNT multiscale composites. Additionally, the conditions for improving the electrical properties were promoted by the insulating factor the MWCNTs provided. The mechanical properties also benefitted from the use of LMWCNTs and SMWCNTs. It could be said that the SMWCNTs showed better performance with a unique value at $10 \mathrm{wt} \%$ without a plausible reasoning.

The research work with different MWCNT sizes and loading levels in fiber-reinforced composites has opened a 

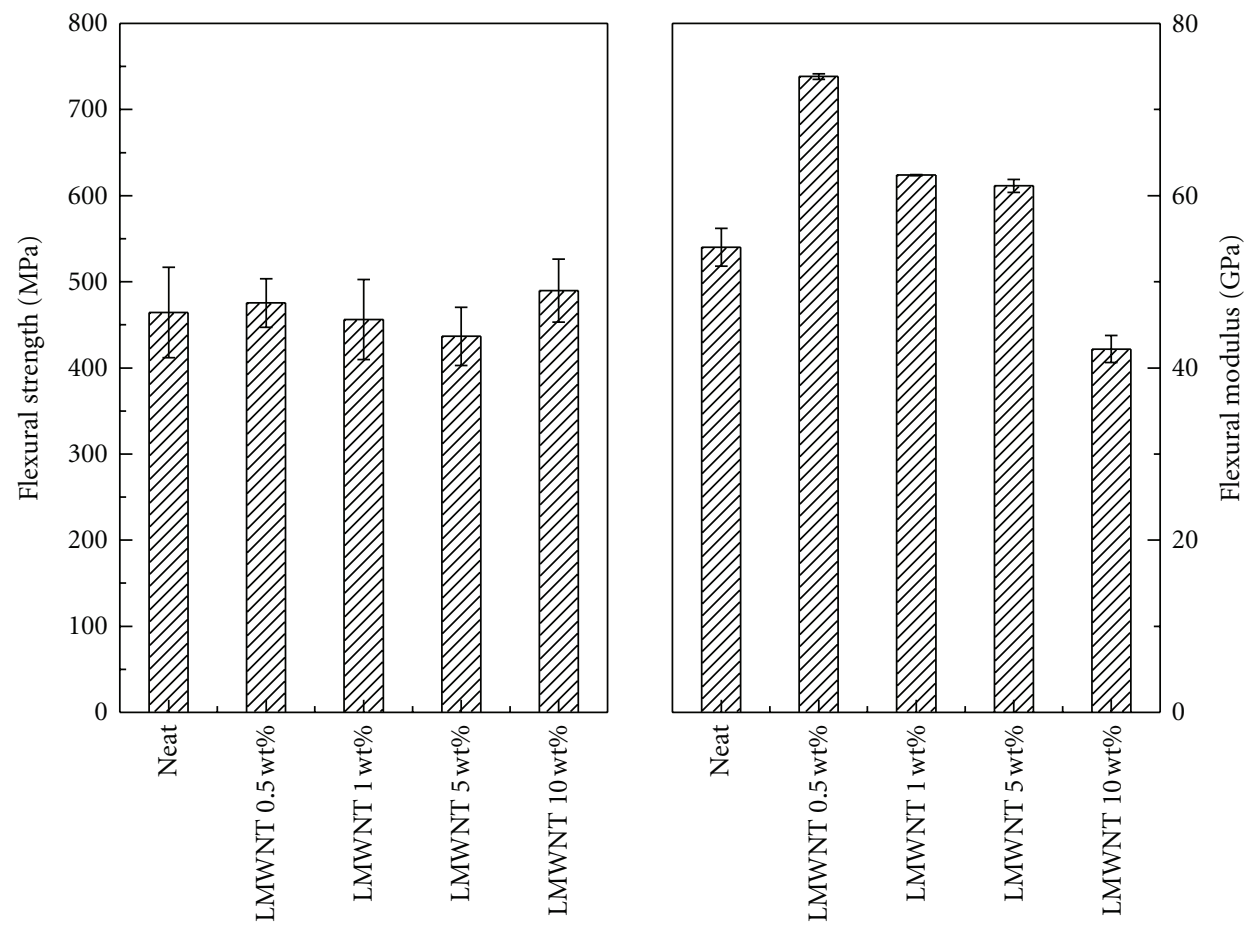

FIGURE 8: Shimadzu 3-point bending LMWCNT multiscale composite flexural modulus and strength test.
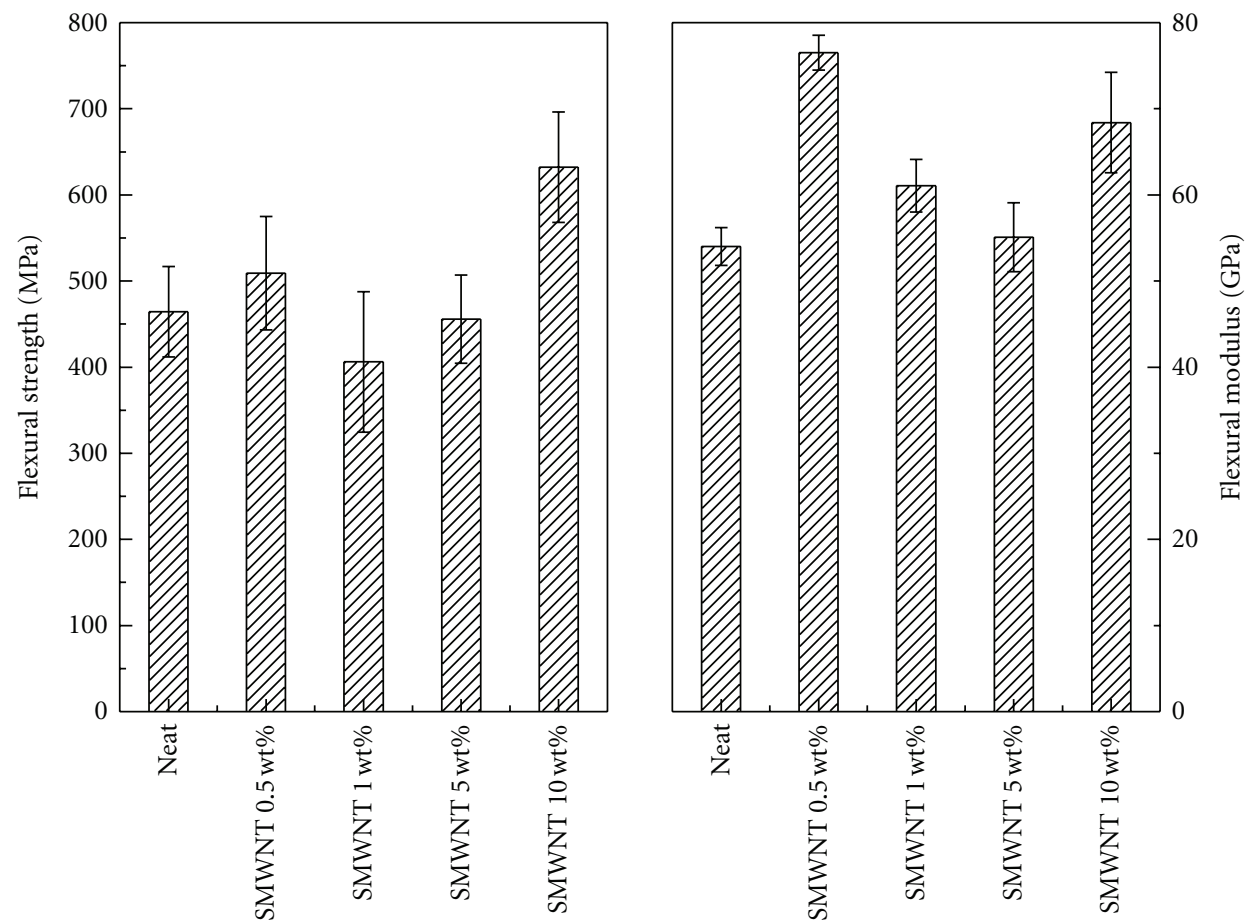

FIGURE 9: Shimadzu 3-point bending SMWCNT multiscale composite flexural modulus and strength test.

new outlook on the expectation of physical performance in multiscale composites. Much has to be explored in the relationship of nanoscale materials in combination of macroand microscale systems. LMWCNTs, at this point, do not significantly advance conventional composite's performance over SMWCNTs.

\section{Acknowledgments}

M. Zimmer acknowledges the support of Q. Cheng and S. Li for their technical advising on experiments. Thanks to J. Brooks for the expertise on the physics background related to the research. Many thanks to R. Liang, B. Wang, and 
C. Zhang for the research advising, financial support, and knowledge provided throughout the term of the research.

\section{References}

[1] E. Bekyarova, E. T. Thostenson, A. Yu et al., "Multiscale carbon nanotube-carbon fiber reinforcement for advanced epoxy composites," Langmuir, vol. 23, no. 7, pp. 3970-3974, 2007.

[2] Y. H. Lu, M. S. Zhan, and W. H. Zheng, "Preparation and properties of T300 carbon fiber-reinforced thermoplastic polyimide composites," Journal of Applied Polymer Science, vol. 102, no. 1, pp. 646-654, 2006.

[3] H. Qian, A. Bismarck, E. S. Greenhalgh, G. Kalinka, and M. S. P. Shaffer, "Hierarchical composites reinforced with carbon nanotube grafted fibers: the potential assessed at the single fiber level," Chemistry of Materials, vol. 20, no. 5, pp. 1862 1869, 2008.

[4] V. K. Rangari, M. Yousuf, S. Jeelani, M. X. Pulikkathara, and V. N. Khabashesku, "Alignment of carbon nanotubes and reinforcing effects in nylon-6 polymer composite fibers," Nanotechnology, vol. 19, no. 24, Article ID 245703, 2008.

[5] S. Z. Shen, S. Bateman, Q. Yuan, M. Dell'Olio, J. Gotama, and D. Y. Wu, "Thermal properties and fire performance of woven glass fibre reinforced nylon 6 nano-composites with carbon nanotubes," Advanced Materials Research, vol. 32, pp. 9-12, 2008.

[6] Z. Fan, M. H. Santare, and S. G. Advani, "Interlaminar shear strength of glass fiber reinforced epoxy composites enhanced with multi-walled carbon nanotubes," Composites Part A, vol. 39, no. 3, pp. 540-554, 2008.

[7] T. Borca-Tasciuc, M. Mazumder, Y. Son, S. K. Pal, L. S. Schadler, and P. M. Ajayan, "Anisotropic thermal diffusivity characterization of aligned carbon nanotube-polymer composites," Journal of Nanoscience and Nanotechnology, vol. 7, no. 4-5, pp. 1581-1588, 2007.

[8] S. Wang, R. Liang, B. Wang, and C. Zhang, "Dispersion and thermal conductivity of carbon nanotube composites," Carbon, vol. 47, no. 1, pp. 53-57, 2009.

[9] W. T. Hong and N. H. Tai, "Investigations on the thermal conductivity of composites reinforced with carbon nanotubes," Diamond and Related Materials, vol. 17, no. 7-10, pp. 15771581, 2008.

[10] Q. Ngo, B. A. Cruden, A. M. Cassell et al., "Thermal conductivity of carbon nanotube composite films," in Proceedings of the Materials Research Society Symposium, vol. 812, pp. 179184, April 2004.

[11] A. Moisala, Q. Li, I. A. Kinloch, and A. H. Windle, "Thermal and electrical conductivity of single- and multi-walled carbon nanotube-epoxy composites," Composites Science and Technology, vol. 66, no. 10, pp. 1285-1288, 2006.

[12] M. B. Bryning, D. E. Milkie, M. F. Islam, J. M. Kikkawa, and A. G. Yodh, "Thermal conductivity and interfacial resistance in single-wall carbon nanotube epoxy composites," Applied Physics Letters, vol. 87, no. 16, Article ID 161909, 3 pages, 2005.

[13] Y. A. Kim, S. Kamio, T. Tajiri et al., "Enhanced thermal conductivity of carbon fiber/phenolic resin composites by the introduction of carbon nanotubes," Applied Physics Letters, vol. 90, no. 9, Article ID 093125, 3 pages, 2007.

[14] L. Tong, X. Sun, and P. Tan, "Effect of long multi-walled carbon nanotubes on delamination toughness of laminated composites," Journal of Composite Materials, vol. 42, no. 1, pp. 5-23, 2008.
[15] C. Zweben, "Thermal materials solve power electronics challenges," Power Electronics Technology, vol. 32, no. 2, pp. 40-47, 2006.

[16] G. W. Lee, M. Park, J. Kim, J. I. Lee, and H. G. Yoon, "Enhanced thermal conductivity of polymer composites filled with hybrid filler," Composites Part A, vol. 37, no. 5, pp. 727734, 2006.

[17] S. Han, J. T. Lin, Y. Yamada, and D. D. L. Chung, "Enhancing the thermal conductivity and compressive modulus of carbon fiber polymer-matrix composites in the through-thickness direction by nanostructuring the interlaminar interface with carbon black," Carbon, vol. 46, no. 7, pp. 1060-1071, 2008.

[18] I. Grigoriev and E. Melilikhov, Handbook of Physical Quantities, CRC Press, New York, NY, USA, 1997.

[19] G. Chen, "Phonon heat conduction in nanostructures," International Journal of Thermal Sciences, vol. 39, no. 4, pp. 471480, 2000.

[20] J. Klett, A. D. Mcmillan, and N. C. Gallego, The Role of Structure on the Thermal Properties of Graphite Foams, Oak Ridge National Laboratory, 2007.

[21] J. Singh, Excitation Energy Transfer Processes in Condensed Matter: Theory and Applications, Plenum Press, New York, NY, USA, 1994.

[22] C. Kittel, Introduction to Solid State Physics, Wiley, New York, NY, USA, 5th edition, 1976.

[23] R. C. Zeller and R. O. Pohl, "Thermal conductivity and specific heat of noncrystalline solids," Physical Review B, vol. 4, no. 6, pp. 2029-2041, 1971.

[24] J. Bodzenta, "Influence of order-disorder transition on thermal conductivity of solids," Chaos, Solitons and Fractals, vol. 10, no. 12, pp. 2087-2098, 1999.

[25] R. S. Prasher, X. J. Hu, Y. Chalopin et al., "Turning carbon nanotubes from exceptional heat conductors into insulators," Physical Review Letters, vol. 102, no. 10, Article ID 105901, 4 pages, 2009.

[26] S. T. Huxtable, D. G. Cahill, S. Shenogin et al., "Interfacial heat flow in carbon nanotube suspensions," Nature Materials, vol. 2, no. 11, pp. 731-734, 2003.

[27] D. Cahill and R. Pohl, "Lattic vibrations and heat transport in crystals," Annual Reviews, vol. 39, pp. 93-121, 1988.

[28] K. Esfarjani, M. Zebarjadi, and Y. Kawazoe, "Thermoelectric properties of a nanocontact made of two-capped single-wall carbon nanotubes calculated within the tight-binding approximation," Physical Review B, vol. 73, no. 8, Article ID 085406, 6 pages, 2006.

[29] C. Yeh, A study of nanostructure and properties of mixed nanotube buckypaper materials: fabrication, process modeling, characterization and property modeling [Ph.D. dissertation], Florida State University, Tallahassee, Fla, USA, 2007.

[30] E. Kymakis, I. Alexandou, and G. A. J. Amaratunga, "Singlewalled carbon nanotube-polymer composites: electrical, optical and structural investigation," Synthetic Metals, vol. 127, no. $1-3$, pp. 59-62, 2002.

[31] A. Buldum and J. P. Lu, "Contact resistance between carbon nanotubes," Physical Review B, vol. 63, no. 16, Article ID 161403, 3 pages, 2001.

[32] R. B. Mathur, S. Chatterjee, and B. P. Singh, "Growth of carbon nanotubes on carbon fibre substrates to produce hybrid/ phenolic composites with improved mechanical properties," Composites Science and Technology, vol. 68, no. 7-8, pp. 16081615, 2008.

[33] J. Qiu, C. Zhang, B. Wang, and R. Liang, "Carbon nanotube integrated multifunctional multiscale composites," Nanotechnology, vol. 18, no. 27, Article ID 275708, 2007. 
[34] R. J. Sager, P. J. Klein, D. C. Lagoudas et al., "Effect of carbon nanotubes on the interfacial shear strength of T650 carbon fiber in an epoxy matrix," Composites Science and Technology, vol. 69, no. 7-8, pp. 898-904, 2009. 

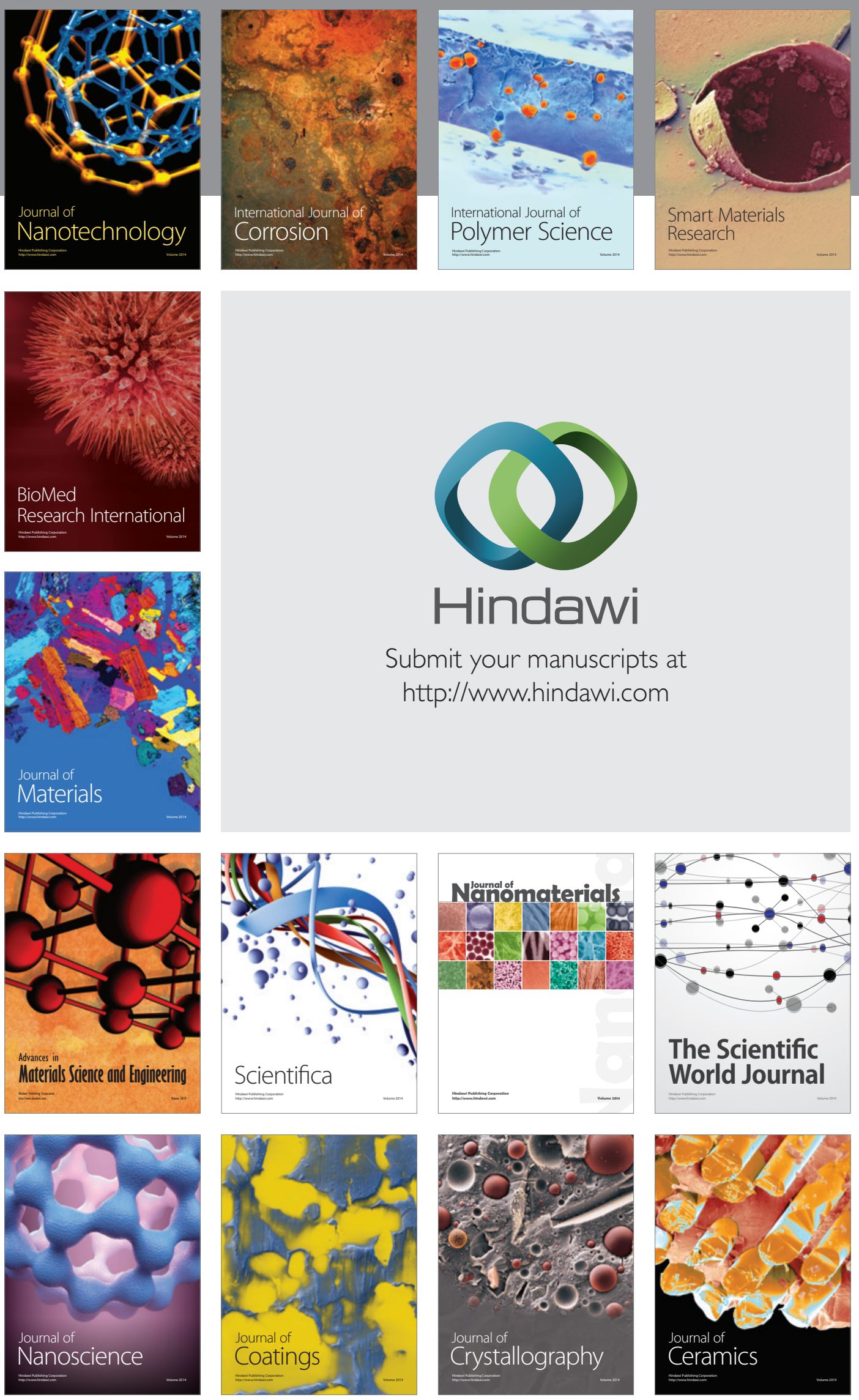

The Scientific World Journal

Submit your manuscripts at

http://www.hindawi.com

\section{World Journal}

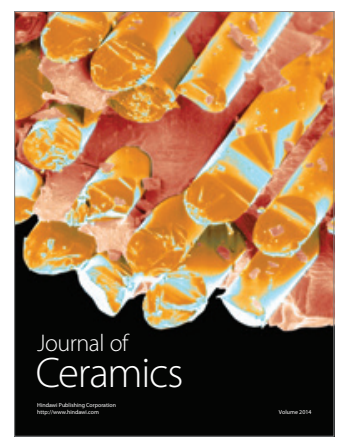

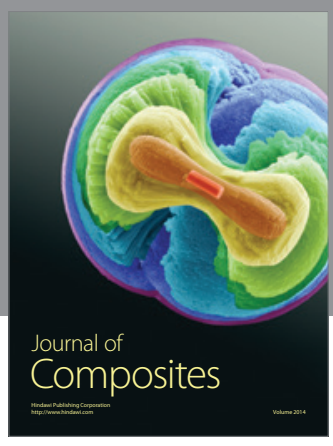
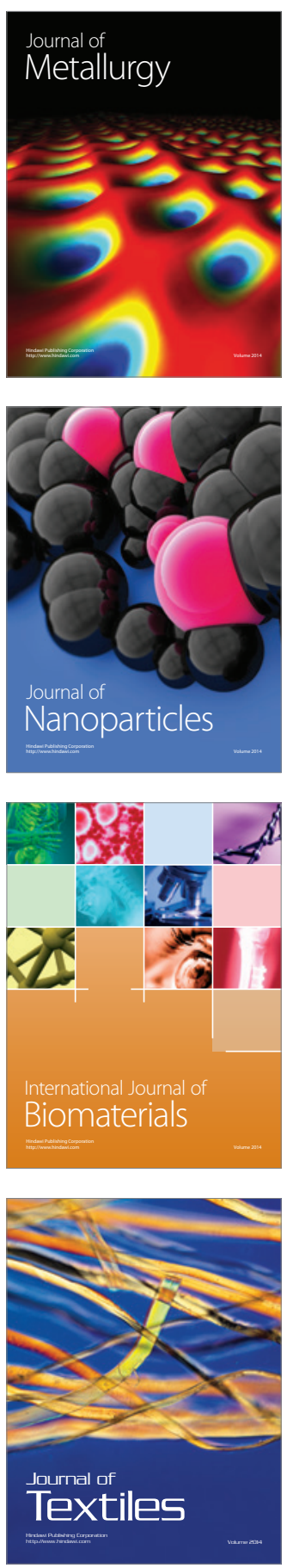